\title{
Factors Contributing Career Change among Nurses working at selected Hospitals
}

\section{Heba Hassona Hassan 1; Safaa Mohamed Abdelrahman 2; Amira Mostafa Fahmy 3 ; Faten Ali Ahmed 4}

1. B.Sc. Nursing, Faculty of Nursing-Minia University, Egypt.

2. Professor of Nursing Administration, Faculty of Nursing-Minia University, Egypt.

3. \& 4 Lecturer of Nursing Administration, Faculty of Nursing-Minia University, Egypt.

\begin{abstract}
Background: Good career choice outcomes should produce a series of positions that give opportunity for good performance, maintain a commitment to the field, and provide high work satisfaction. Aim: to investigate factors contributing to career change among nursing staff. Research design: A descriptive research design was utilized to fulfill the aim of the study. Subjects: a convenience sample of staff nurses their age under 40 years working at Minia University and Fever Hospitals during the period of data collection. Setting: Fever Hospital and Minia university hospitals in Minia city, Egypt. Data collection tools included three tools; first personal data, second, anticipated career change factors, and third, social factors. Results: $82.0 \%, 80.5 \%, 77.3$, and $52.3 \%$ of the studied nurses have moderate total anticipated factors, job satisfaction, burnout level, and autonomy respectively, while $64.1 \%, 41.4 \%$, $21.1 \%, 18.0 \%, 14.8 \%$ of them had high-level workload, autonomy, burnout, anticipated factors, and job satisfaction respectively. Moreover, $53.1 \%$ of the studied nurses have moderate social factors to career change, $44.5 \%$ have high levels, and 2.3\% have low levels. Conclusion: This study revealed that nearly two-thirds of the studied nurses mentioned that the main factors for career change were workload and social factors. Recommendation: develop advanced career ladder for better advancement, high job satisfaction, autonomy and low burnout and career change.
\end{abstract} Keywords: Career change, Factors, Nurses, Nursing Career

\section{Introduction}

Good career choice outcomes should produce a series of positions that give opportunity for good performance, maintain a commitment to the field, and give high work satisfaction. In Egypt, nursing was considered as a chance to work in other countries. The image of nursing as a profession is affected by numerous factors that decide nursing as a career. These factors include media, public image, social prestige, nurses themselves, having a family member, relative, or a friend who is a nurse, role models, physician-nurse interaction, nursing educators, nurse preceptors, risk for violence, exposure to health hazards, and nursing education programs (Ali, 2017).

Nursing is defined as the protection, promotion, and optimization of health and abilities, prevention of illness and injury, alleviation of suffering through the diagnosis and treatment of human response, and advocacy in the care of individuals, families, communities, and populations. It is also defined as the use of clinical judgment in the provision of care to enable people to improve, maintain, or recover health, to cope with health problems, and to achieve the best possible quality of life, whatever their disease or disability, until death (Kaur, Kanika, \& Kumar, 2016).

The patient-nurse-staff ratios are directly associated with turnover intention levels in hospitals. The highperforming hospitals have an elevated level of nurse involvement and a flat management structure, and life-long learning is inculcated in the organizational culture. When structural empowerment is ingrained into a healthcare organization's processes, organizational leaders are accessible and receptive to employee concerns, nurses can participate in policy decisions, and are involved in the governance of the organization, specifically related to their practice and nursing units (Lo, Chien, Hwang, Huang, \& Chiou, 2018).

Career change is alternatively defined as any major change in work-role requirements or work context and as a process that may result in a change of job, profession, or a change in one's orientation to work. Career change is 'the movement of a person from one job group to another (Ibarra, 2018). In nursing context, career change occurs when registered nurse may leave the nursing field to work in a different industry. Moreover, nurses who have been leaving profession were defined as follows: 'a nurse who voluntarily discontinues nursing profession after working a certain time after graduation from the school of nursing'(Chang et al., 2015)

Career change in relation to job refers to changes in the staff some leave and new employees begin. Turnover intentions, however, intention to change job- are considered an outcome of affective variables, while actual turnover also includes nurses retiring and leaving involuntarily. Turnover intention also measures what influences the nurses and makes them want to quit (Andresen et al., 2017).

One in four nurses wants to leave the job. The high turnover rate of nurses frequently results in a decrease in job satisfaction for the remaining nurses. Job satisfaction is a concept incorporating each of the nurses' subjective opinions on their 'satisfaction with the job (Valizadeh et al., 2016).

Therefore, there is a need to increase the recruitment of nurses into healthcare institutions and devise ways to retain the nurses. This is a major challenge in today's nursing shortage environment as many factors determine the reasons why a Registered Nurse (RN) would accept a certain job whether they will still work in the same institution after the employment or move to other more gainful areas of employment (Goodare, 2017).

There are many factors that have a major and decisive role to frame the nurses career change; which can be wages, job satisfaction, growth of the career, service conditions, work environment, style of supervisor, employee commitment, support of manager, organizational culture, and policies that support human resource. Career change of nurses 
is the results from number of pressures and attractive factors that can be done during the relationship of employment (Barthauer et al., 2020; Acosta-Ramos et al., 2021)

Moreover, there are various factors which implicit high rates of career change among nurses. These factors include high burnout, insufficiency of career development, poor advocacy from supervisors with shortage of autonomy in making the decision, pauper communication and connection within the organization, low self-esteem, ambiguity of role, high workload with insufficient income, and the exposition to injuries whether it is physically or psychologically (Al Shaibani et al., 2020; Brzostek, 2020; \& Garcia and Marziale, 2021)

\section{Significance of The Study}

During the researcher work in fever hospital as a professional nurse, I noticed that there is an observable degree of dissatisfaction with nurse's career, and there is intent to leave and change nursing career as a whole.

Nursing manpower is one of the most important healthcare organizations that represent a critical element in their success. When there are career changes, the quality of care provided to the population will be at risk. Efforts to retain nurses within the profession are critical for resolving the global nursing shortage, but very little research explores the factors affecting career changes in Egypt.

A recent study done in Middle Egypt by Ahmed et al., (2017) explored career changes and organizational commitment among staff nurses in a selected hospital at BeniSuef city. It revealed that staff nurses had higher career changes in their hospitals and had a moderate level of total organizational commitment. There was a statistically significant negative correlation between organizational commitment and career changes among the nursing profession.

Also, a recent study done in Upper Egypt by Ali, (2017) to determine the societal factors that induce career change decisions among nurses working at different Sohag city hospitals revealed a highly statistically significant positive correlation between societal satisfaction and participants' decision to leave the nursing career.

\section{Subjects and methods \\ Aim of the Study}

The current study aims to investigate factors contributing to career change among nursing staff.

\section{Research Questions:}

1. What are factors contributing to career change among nurses?

2. Is there a relation between factors contributing to career change among nurses and their socio-demographic data?

\section{Research Design}

A descriptive research design was utilized to fulfill the aim of this study.

\section{Setting:}

The study was conducted randomly at Fever Hospital and Minia University Hospital, Fever Hospital located in alhamiyaat square , El Minia 'Minia Governorate, Egypt, this hospital was consisted of three building; The first building contain four floors; the first floor contains the emergency
Department, radiology, pharmacy, and all out patients clinics. The second floor contains; infection control team, quality team, nursing directors. The third floor contains isolation Department and investigation lab the fourth floor contain PCR lab. The second building contains three floors; the first contain dialysis unite, The second and third floor contain all in patients Departments. The third building contain two floors ; the first floor contains the HIV Department, The second floor contains hospital administration.

Minia Uuniversity Hospital located in Kurnish al/Nile street, El Minia ‘Minia Governorate, this hospital was consisted of three building; The first building contains one floor; this floor contains the emergency Department, pharmacy, and all outpatients clinics. The second building contains three floors; infection control team, quality team, Operating Rooms (OR) and Intensive Care Units (ICUs), The second floor contains investigation lab, and poison unit. The third floor contains; all inpatients Departments. The third building contains two floors; which contain all inpatient administrative Departments.

\section{Subjects}

The study sample subjects included a convenience sample of staff nurses their age under 40 years working in Minia University and Fever Hospitals during the data collection period. Their total number was 128 nurses.

\begin{tabular}{|l|l|l|l|l|}
\hline \multicolumn{2}{|c|}{ Categories } & Male & Female & \multirow{2}{*}{ Total } \\
\hline \multirow{2}{*}{$\begin{array}{l}\text { Minia } \\
\text { University } \\
\text { hospital }\end{array}$} & B.CS & 3 & 10 & \multirow{6}{*}{68} \\
\cline { 2 - 4 } & Institute & 6 & 15 & \\
\cline { 2 - 4 } $\begin{array}{l}\text { Fever } \\
\text { hospital }\end{array}$ & Diplom & 9 & 25 & \multirow{3}{*}{60} \\
\cline { 2 - 4 } & B.CS & 1 & 20 & \multirow{2}{*}{128} \\
\cline { 2 - 4 } & Institute & 6 & 20 & \\
\hline
\end{tabular}

Inclusion criteria

- Male and female

- Under 40 years

- On working time

\section{Data Collection Tools}

Data was collected through the utilization of three scales as follows:

Tool (1): It was included three parts:

\section{Part I: Personal data}

It was used to collect data about nurses and encompass age, gender, marital status, residence, educational level, salary, and years of experience, place of work, health, and time spend with their family.

\section{Part II: Factors contributing to career change questionnaire}

It consists of four dimensions autonomy, job satisfaction, Burnout, and workload.

\section{1) Autonomy}

Autonomy Likert scale: it was adopted from Blegen et al., (1993) to measure nurses' work autonomy. The researcher makes necessary adjustments and changes according to the nature of the selected topic.

Scoring system: The scale contains 12 items with responses ranging from 1 to 3 as the following (agree- neutraldisagree) with a scoring system (1-2-3) respectively. A total score of less than $50 \%$ was considered low, $50 \%-75 \%$ moderate, $75 \%$ or more high autonomy. 


\section{2) Satisfaction}

Job satisfaction scale: it was adopted from Mueller and McCloskey, (1990), it consists of 25 items.

Scoring system: the responses were scored under three-points Likert scales, as 1 (dissatisfied), 2 (neutral), 3 (satisfied), Total score less than $50 \%$ was considered as low satisfaction, $50 \%-75 \%$ moderate job satisfaction, $75 \%$ or more was high job satisfaction.

\section{3) Burnout}

Burnout Inventory (MBI): it was adopted from Maslach and Jackson (2016), necessary changes were done according to the researcher's research needs after reviewing the literature. It contains (10) items with responses ranging from 1 to 3 as the following (often-always-never), with the scoring system (1-2-3) respectively. Total score less than 50\% was considered low burnout, $50 \%-75 \%$ moderate burnout, $75 \%$ or more was high burnout.

\section{4) Workload}

Workload it was adopted from Rosen et al. (2018), consist of (9) items, with responses ranging from 1 to 3 as the following (agree-neutral-disagree) with the scoring system (1$2-3)$ respectively. Total score less than $50 \%$ was considered low workload, $50 \%-75 \%$ moderate workload, $75 \%$ or more was high workload.

\section{Part III: Social factors}

It was adopted from Ali, (2017) to determine social factors included the society in Upper Egypt respects nursing career and their employee, the societal view of the reasoning of entering nursing is the need for money, society views nurses who work at night shifts as if they have a deviant behavior, nurses' behavior and attitude are suspected in the society, mass media show nurses in bad behavior, being a nurse does not affect their relations in the society, the family respects them as a nurse and supports them all the time when they decided to be a nurse, the family supports them, the Egyptian laws and legislation protect nursing, and they think that the Egyptian Nursing Syndicate support nurses everywhere.

Social factors Likert scale: it consists of 10 items that assess the participants' perception about possible societal factors that affect nurses' career change. With scoring system: 1 (disagree), 2 (neutral), and 3 (agree). Total score less than $50 \%$ was considered low effect of social factors, $50 \%-75 \%$ moderate effect of social factors, $75 \%$ or more were high effect of social factors.

\section{Validity and Reliability of Tool:}

The tool was submitted to a jury of 5 experts in the field of nursing administration field to determine its applicability and content validity, and modification was done.

Reliability of the tools ( tool: II, III) was performed to confirm the validity of the tool and calculated statistically. The internal consistency was measured to identify the extent to which the items of the tool measure the same concept and correlate with each other by Cronbach's alpha test.
Cronbach's alpha reliability test for tools of data collection

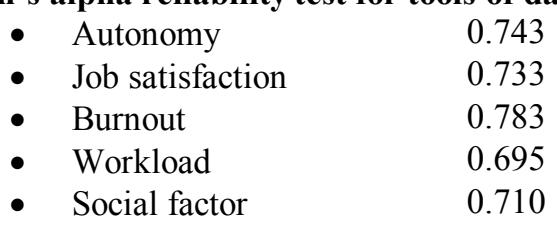

Pilot Study:

A pilot study was carried out before starting data collection on $10 \%$ of nurses from Fever Hospital and Minia university hospital. This pilot study aims to test the clarity, comprehensiveness, accessibility, and applicability of tools and estimate the appropriate time required to fill the questionnaire. It also served to estimate the time required for filling the questionnaire sheets, which was about 20 minutes. They were included in the main study subjects during the actual collection of data. The process of pilot study took two weeks (from 05/1 to 20/1) in January 2020.

\section{Ethical Considerations:}

A written initial approval was obtained from the research ethics committee of the Faculty of Nursing, Minia University. An informed consent was obtained from the Undersecretary of the Ministry of Health and Minia University. Collecting the study data before data collection, after explanation of the purpose of the study, the participants were informed that their participation in the study was completely voluntary and there was no harm if they not participate in the study. Confidentiality, anonymity and privacy were assured.

\section{Data Collection Procedure:}

Approval to conduct the study was obtained from the Undersecretary of the Ministry of Health and Minia University, Meet directors of Fever Hospital and Minia university Hospital to gain cooperation . Questionnaire was translated from English language to Arabic language. Participant was self administred questionnaire_to explain the nature and purpose of the study. The questionnaire was distributed for nurses to fill it. After distribution of the sheet, the researcher explained the content of each part of the tool. Nurses Participant was meet in a groups to explain the purpose of this study. Each group consisted of five to seven nurses. Then, the questionnaire was introduced for nurses to be filled. After distribution of the sheet, the researcher explained the content of each part of the tool. Data collection was done during the morning, afternoon, and night shifts two days/week, from January to June 2020.

\section{Data processing and analysis:}

data of this study were processed and analyzed using number of sheets collected from the study subject as follows: For Minia University Hospital (sheets $=68$ ), and for Fever Hospital (sheets $=60$ ). Data were fed to the computer and statistical analysis was performed using Statistical Package for Social Sciences (SPSS version 20). Significance of the obtained results was judged at the $5 \%$ level of significance. Quantitative data were expressed as frequency and percentage. For quantitative data, comparison between two variables was done using t-test, and comparison between more than two variables used ANOVA test. Probability ( $p$-value) Vless than 0.05 was considered significant 


\section{Results}

Table (1): Distribution of the staff nurse personal characteristics $(n=128)$.

\begin{tabular}{|c|c|c|c|}
\hline & Characteristics & No. & $\%$ \\
\hline \multicolumn{4}{|l|}{ Age } \\
\hline - $20-30 \mathrm{yrs}$ & & $\mathrm{VT}$ & ov, , \\
\hline - $\quad 31-40 \mathrm{yrs}$ & & 00 & $\varepsilon r, \cdot$ \\
\hline \multicolumn{2}{|l|}{ Mean +SD } & \multicolumn{2}{|c|}{$30.3 \pm 5.4$ years } \\
\hline \multicolumn{2}{|l|}{ Gender } & & \\
\hline Male & & TA & $r, 9$ \\
\hline - $\quad$ Female & & $1 \cdots$ & $V \wedge, 1$ \\
\hline \multicolumn{4}{|l|}{ Educational level } \\
\hline Diploma & & 07 & $\varepsilon r, \wedge$ \\
\hline - $\quad$ Institute & & $\varepsilon \wedge$ & $r v, \varepsilon$ \\
\hline Bachelor & & $r \varepsilon$ & $1 \wedge, 1$ \\
\hline \multicolumn{4}{|l|}{ Residence } \\
\hline - $\quad$ Rural & & $\varepsilon V$ & $\Delta V, 1$ \\
\hline Urban & & $0 \leqslant$ & $\varepsilon Y, Y$ \\
\hline \multicolumn{4}{|l|}{ Marital status } \\
\hline - $\quad$ Single & & $r$ & $r \leqslant, r$ \\
\hline - $\quad$ Married & & 91 & $v, 1$ \\
\hline - $\quad$ Divorced & & 0 & $r, 9$ \\
\hline - Widow & & 1 & .8 \\
\hline \multicolumn{4}{|l|}{ Salary } \\
\hline - $\quad$ Satisfied & & 10 & 11.7 \\
\hline - $\quad$ Unsatisfied & & 113 & 88.3 \\
\hline \multicolumn{4}{|l|}{ Experience years } \\
\hline - $1-10 \mathrm{yrs}$ & & $\mathrm{Vq}$ & 61.7 \\
\hline - $11-21 \mathrm{yrs}$ & & $\sum 9$ & 38.3 \\
\hline
\end{tabular}

Table (1): shows that the mean age of studied nurses was $30.3 \pm 5.4$ years. Regarding gender, $78.1 \%$ of the studied nurses were females, $43.8 \%$ had diploma nursing, and 57.8\% lived in rural areas. Concerning marital status, $71.1 \%$ of the studied nurses were married, $88.3 \%$ of them had unsatisfied with their salary, and $61.7 \%$ of them had $1-<10$ years' experience in the nursing field.

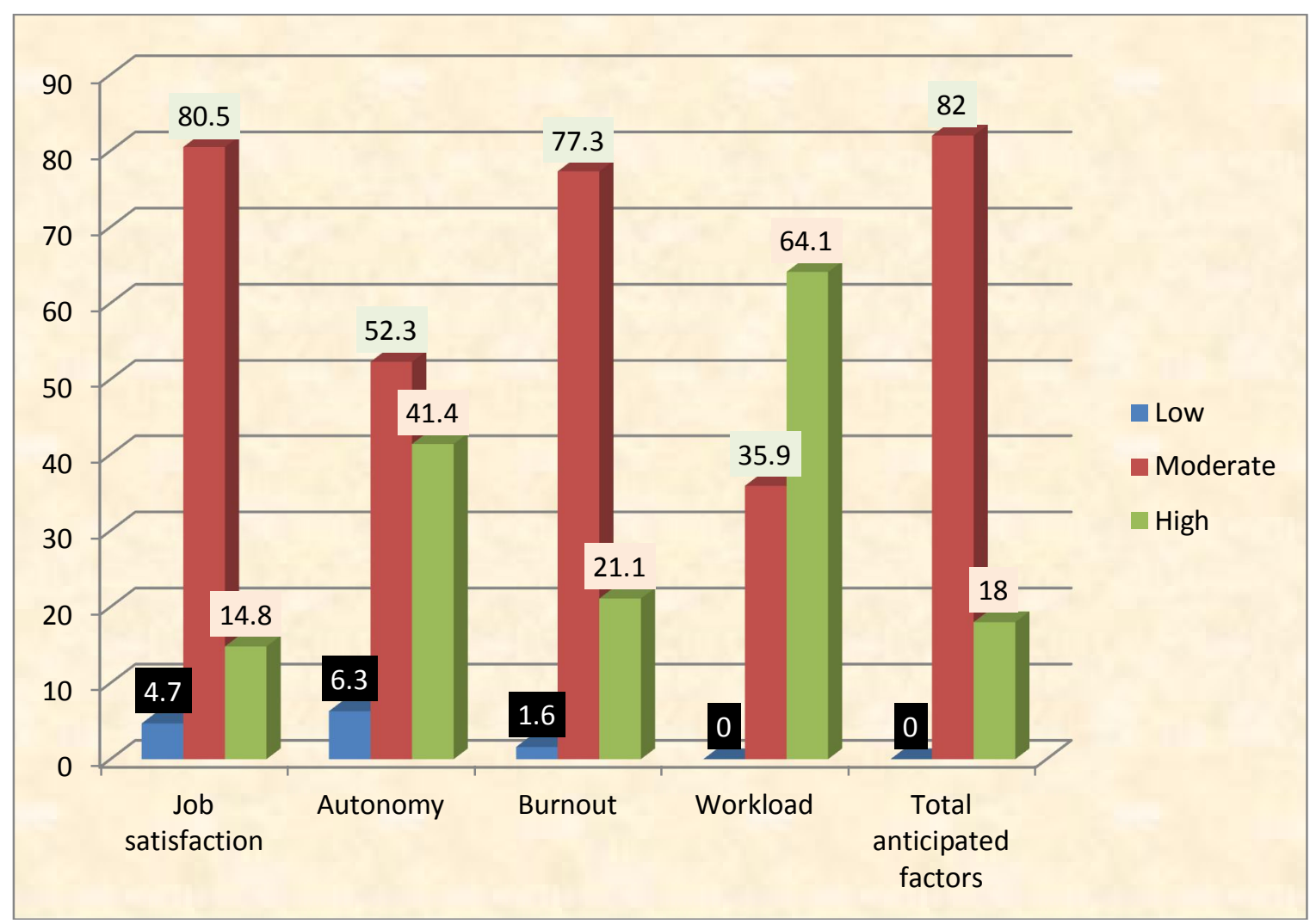

Figure (1): Levels of factors contributing to a career change among the studied staff nurses (N=128).

Figure (1): illustrates that $82.0 \%, 80.5 \%, 77.3$, and $52.3 \%$ of the studied nurses had moderate level of total anticipated factors, job satisfaction, burnout level, and autonomy, respectively, while $64.1 \%, 41.4 \%, 21.1 \%, 18.0 \%, 14.8 \%$ of them had high-level 


\section{Total social factor $\quad$ Low}

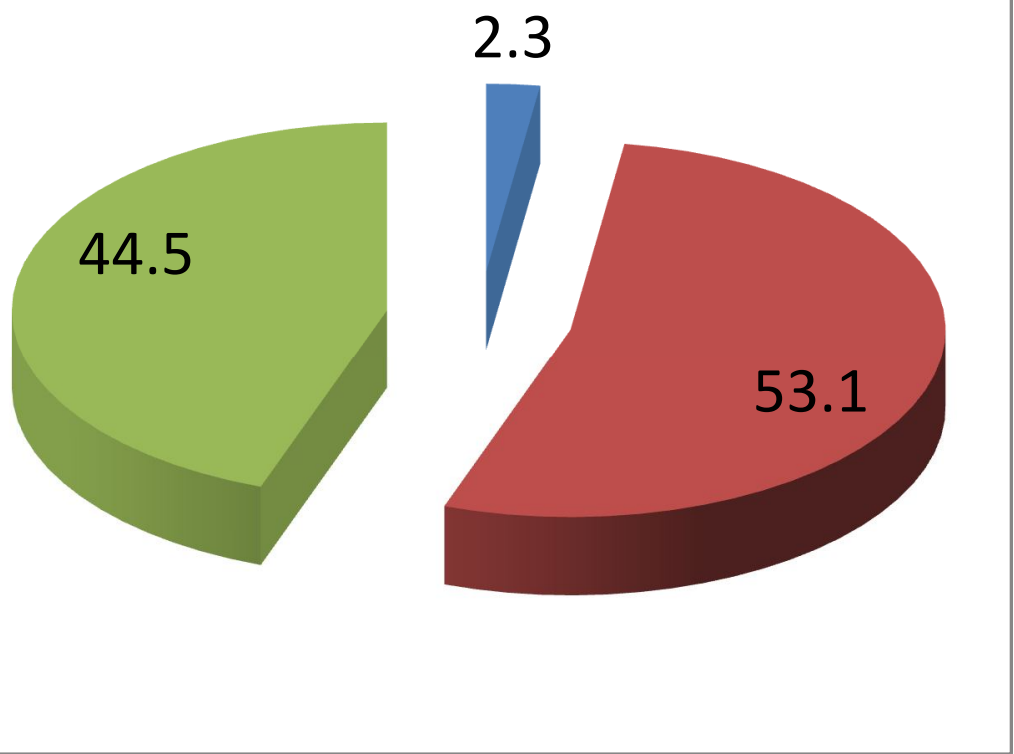

Figure (2): Levels of social factors contributing to a career change among the studied staff nurses' $(\mathrm{N}=128)$.

Figure (2): illustrates that $53.1 \%$ of the studied nurses had moderate social factors to career change, $44.5 \%$ of them had a high level, and $2.3 \%$ had low levels.

Table (2) Mean scores of Factors Contributing Career Change among staff nurses (n=128)

\begin{tabular}{|c|c|c|c|c|c|c|c|c|}
\hline \multirow{3}{*}{$\begin{array}{c}\text { Anticipated factor } \\
\text { dimensions }\end{array}$} & \multicolumn{6}{|c|}{ Staff nurses $(n=128)$} & \multirow{3}{*}{ T-test } & \multirow{3}{*}{$\mathbf{P}$} \\
\hline & \multicolumn{3}{|c|}{$\begin{array}{l}\text { Minia University hospital } \\
(\mathrm{N}=68)\end{array}$} & \multicolumn{3}{|c|}{$\begin{array}{c}\text { Fever hospital } \\
(\mathrm{N}=60)\end{array}$} & & \\
\hline & Mean + SD & Min & Max & Mean \pm SD & Min & Max & & \\
\hline Autonomy & $25.89 \pm 4.80$ & 16 & 36 & $27.38+4.20$ & 18 & 36 & 1.85 & $\begin{array}{l}.067 \\
\text { NS }\end{array}$ \\
\hline Job satisfaction & $49.83+5.95$ & 37 & 64 & $52.78+6.76$ & 33 & 73 & 2.61 & $.010^{*}$ \\
\hline Burnout & $20.85 \pm 2.33$ & 15 & 27 & $21.81 \pm 2.55$ & 16 & 28 & 2.22 & $.028^{*}$ \\
\hline Workload & $21.25 \pm 2.62$ & 15 & 25 & $21.38 \pm 2.55$ & 15 & 26 & 0.290 & $\begin{array}{l}.772 \\
\text { NS }\end{array}$ \\
\hline Social factor & $22.47 \pm 3.15$ & 14 & 28 & $22.60 \pm 2.49$ & 16 & 27 & 0.255 & $\begin{array}{l}.799 \\
\text { NS }\end{array}$ \\
\hline
\end{tabular}

T-test was used for quantitative data, *Significant difference between groups (p-value $\leq 0.05)$, NS= Not Significant difference.

Table (2): presents that mean scores of job satisfaction and Burnout are higher among studied nurses in fever hospital than studied nurses in Minia university hospital with statistically significant differences $p$-value $\leq .01 \& .028$ respectively.

Table (3) Mean scores comparison between of Factors Contributing Career Change among staff nurses educational qualification $(\mathbf{n}=\mathbf{1 2 8})$

\begin{tabular}{|c|c|c|c|c|c|}
\hline \multirow{3}{*}{$\begin{array}{l}\text { Anticipated factor } \\
\text { dimensions }\end{array}$} & & nurses $(n=1$ & & \multirow{3}{*}{$\begin{array}{c}\text { Anovates } \\
\mathbf{t}\end{array}$} & \multirow{3}{*}{$\mathbf{P}$} \\
\hline & $\begin{array}{c}\text { Diploma } \\
\text { N-56 }\end{array}$ & $\begin{array}{c}\text { Technical } \\
\mathrm{N}=48 \\
\end{array}$ & $\begin{array}{c}\text { Bachelor } \\
\mathrm{N}=\mathbf{2 4} \\
\end{array}$ & & \\
\hline & Mean +SD & Mean +SD & Mean +SD & & \\
\hline Job satisfaction & $51.03 \pm 7.17$ & $51.00 \pm 6.15$ & $52.08+5.60$ & .259 & .722 \\
\hline Autonomy & $25.89 \pm 4.83$ & $26.1+4.24$ & $29.04 \pm 3.45$ & 4.51 & $.013 *$ \\
\hline Burnout & $21.98+2.30$ & $20.79+2.67$ & $20.75+2.15$ & 3.88 & $.023 *$ \\
\hline Workload & $21.12+2.82$ & $21.33+2.53$ & $21.70+2.09$ & .427 & .653 \\
\hline Social factor & $22.75 \pm 3.28$ & $22.97 \pm 2.22$ & $21.12 \pm 2.54$ & 3.83 & $.024 *$ \\
\hline
\end{tabular}

ANOVA- test was used for quantitative data, *Significant difference in between groups (p-value $\leq 0.05) \quad$ NS= Not Significant difference

Table (3): presents that mean scores $(21.98 \pm 2.30)$ of diploma nurses higher than other educational qualifications regarding Burnout with statistically significant differences, mean scores $(22.97 \pm 2.22)$ of technical nurses higher than other educational qualifications regarding positive social view with statistically significant differences, and mean scores (29.04 \pm 3.45$)$ of bachelor nurses higher than other educational qualification regarding autonomy with statistically significant differences but mean scores $(52.08+5.60)$ of bachelor nurse higher than other educational qualification regarding job satisfaction and workload dimension with no 
statistically significant differences.

Table (4) Mean scores comparison between of Factors Contributing Career Change and gender among staff nurses (n=128)

\begin{tabular}{|c|c|c|c|c|}
\hline \multirow{3}{*}{ Anticipated factor dimensions } & \multicolumn{2}{|c|}{ Staff nurses $(n=128)$} & \multirow{3}{*}{$\begin{array}{r}\mathbf{T} \\
\text { Test }\end{array}$} & \multirow{3}{*}{$\mathbf{P}$} \\
\hline & Male $(\mathrm{N}=\mathbf{2 8})$ & Female $(\mathrm{N}=100)$ & & \\
\hline & Mean +SD & Mean +SD & & \\
\hline Job satisfaction & $50.21+\overline{6} .17$ & $51.50+6.58$ & .925 & .356 (NS) \\
\hline Autonomy & $25.00+5.14$ & $27.04+4.32$ & 2.11 & $.037^{*}$ \\
\hline Burnout & $20.35 \pm 2.34$ & $21.57 \pm 2.46$ & 2.32 & $.022 *$ \\
\hline Workload & $20.92 \pm 2.76$ & $21.42 \pm 2.53$ & .889 & $.376(\mathrm{NS})$ \\
\hline Social factor & $23.35+1.83$ & $22.30+3.04 \mathrm{~s}$ & 1.74 & .083 (NS) \\
\hline
\end{tabular}

T-test was used for quantitative data, *Significant difference in two groups (p-value $\leq 0.05) \quad$ NS= Not Significant difference.

Table (4): shows that mean scores $(27.04 \pm 4.32 \& 21.57 \pm 2.46$ respectively) of female nurses higher than male nurses regarding autonomy and burnout with statistically significant differences. In comparison, mean scores $(51.50 \pm 6.58 \& 21.42 \pm 2.53$ respectively) of female nurses were higher than male nurses regarding job satisfaction and workload dimension with no statistically significant differences but mean scores $(23.35 \pm 1.83)$ of male nurses were higher than female nurses regarding positive social view dimension with no statistically significant differences.

\section{Discussion}

Nurses have demonstrated the ability to deliver highquality, cost-effective healthcare with concomitant high patient satisfaction. Healthcare organizations require a stable, highly trained, and fully engaged nursing staff to provide effective levels of patient care. Those who are leaving the profession are reducing the total number of nurses in the manpower, which impacts the present nursing shortage and leads to a permanent loss of productivity (Woo, Lee, \& San Tam, 2017).

Regarding personal data of the studied nurses, the present study showed that the mean age of studied nurses was $30.3 \pm 5.4$ years. Regarding gender, more than three-quarters of the studied nurses were female, more than two-fifth of them had diploma nursing, and more than half of them lived in a rural area. Concerning marital status, more than two-thirds of the studied nurses were married, most of them had unsatisfied with their salary, and less than two-thirds of them had $1-<10$ years' experience in the nursing field.

This result comes in accordance with Said \& ElShafei, (2020), who studied " Occupational stress, job satisfaction, and intent to leave: nurses working on front lines during COVID-19 pandemic in Zagazig City, Egypt"and reported that more than half of the studied nurses were less than 30 years, the most of them were females, one-third of them had nursing institute and the years of experience range from 1:10 years and Mohammed et al., (2020) who studied "factors influencing career development among nursing staff at port-said governmental hospitals" and mentioned that the mean age of studied nurses was $32.9 \pm 9.5$ years. Regarding gender, most of the studied nurses were females, and more than half of them had diploma nursing. Concerning marital status, more than two-thirds of the studied nurses were married, and less than two-thirds of them had $1-<10$ years' experience in the current position.

Concerning the nurses' career change, the current results show that the highest factors for nurses' career changes were workload, followed by job autonomy, then work burnout, and finally, job satisfaction.

This result was consistent with Yarbrough et al., (2016) studied "professional values, job satisfaction, career development, and intent to stay " and reported that job satisfaction was strongly correlated with retention, and Leone et al. (2015), who studied " work environment issues and intention-to-leave in Portuguese nurses: a cross-sectional study" and mentioned that workload had been shown to have an effect on nurses' intention to leave.

$P$ a g e | 16
Also, Heinen et al. (2013) studied "Nurses' intention to leave their profession: A cross-sectional observational study in 10 European countries" and found that burnout could initiate career changes or enhance intentions to leave the profession. However, Chang et al., (2018) said that the literature has not sufficiently clarified the process variables that link burnout to a nursing career change.

Regarding total score of social factors to career change, more than half of the studied nurses had moderate level of social factors to career change, less than half of them had a high level, and the minority of them had low levels. This result comes in accordance with Ali, (2017), who studied and reported that most of the studied sample had social factors to career change, and there was a highly statistically significant positive correlation between societal satisfaction and participants' decision to leave the nursing career.

Regarding the comparison between factors contributing to career change and educational qualification among staff nurses, the present study showed that the mean scores of diploma nurses higher than other educational qualifications regarding burnout with statistically significant differences, mean scores of technical nurses higher than other educational qualifications regarding positive social view with statistically significant differences, and mean scores of bachelor nurse higher than other educational qualifications regarding autonomy with statistically significant differences but mean scores of bachelor nurse higher than other educational qualification regarding job satisfaction and workload dimension with no statistically significant differences. This may be related to that diploma nurses work as bedside nurses until retirement comparing with those who had a bachelor degree or master degree who are functionally promoted.

This result comes in line with Ali, (2017), who reported that nurses $(\mathrm{n}=58,65.17 \%)$ who had diploma degrees decided to change comparing with nurses $(n=2$, $100 \%$ ) who had master's degrees decided to stay. There was a significant negative correlation between career change decisions and level of education and workplace.

Regarding the mean score comparison between factors contributing to career change and gender among staff nurses', the current study showed that mean scores of female nurses higher than male nurses regarding autonomy and burnout with statistically significant differences. In comparison, mean scores of female nurses were higher than male nurses regarding job satisfaction and workload dimension with no statistically significant differences but

Heba H., et al 
mean scores of male nurses were higher than female nurses regarding positive social view dimension with no statistically significant differences. This may be due to that the female nurse is more patient than the male.

This result is inconsistent with Ali, (2017), who studied and reported that more than three-quarters of the male nurses decided to stay in a career compared with two-fifth of female nurses. Sex had a significant positive correlation with career change decisions $(P=0.000)$.

Also, this result was supported by Boughn (2001), who studied "Why women and men choose to nurse" and reported that, when participants were asked to rate their reasons for entering nursing, female nurses rated individual fulfillment higher than male nurses, and men were more likely to rate career opportunities. In addition, this result comes in accordance with Fooladi (2003), who studied "Gendered nursing education and practice in Iran" and reported that Iranian male nursing students lack interest in compassionate nursing care and view nursing as a source of income and security.

\section{Conclusion}

It can be concluded from the current study that the mean age of studied nurses was $30.3 \pm 5.4$ years. Regarding gender, more than three-quarters of the studied nurses were females, more than one-third of them had diploma nursing, and more than half of them lived in a rural area. Concerning marital status, more than two-thirds of the studied nurses were married, the majority of them had unsatisfied with their salary, and more than half of them had $1-<10$ years' experience in the nursing field.

Moreover, from this study, it can be concluded that nearly to two-thirds of the studied nurses mentioned that the main factors for career change were workload, social factors, and burnout, and mean scores of diploma nurses higher than other educational qualifications regarding burnout with statistically significant differences, mean scores of technical nurses higher than other educational qualifications regarding positive social view with statistically significant differences, but mean scores of bachelor nurse was higher than other educational qualifications regarding workload dimension with no statistically significant differences.

\section{Recommendations}

Based on the findings of the current study, the

\section{following recommendations are made.}

1. Reducing nurses' workload by determining their practical responsibilities while assigning administrators to specific staff besides hiring nursing assistants to provide indirect care to patients.

2. Improving society's view of nursing work through television programs and interviews, films and series, seminars, and honorable nursing models in Egyptian society.

3. Continuous training and rehabilitation courses to nurses who have a nursing diploma to reduce burnout.

\section{References}

(1) Acosta-Ramos, S., Ramirez-Martinez, F. R., RevelesManriquez, J. I., Galindo-Odilon, M., Estrada-Esparza, S. Y., Trejo-Franco, J., \& Flores-Padilla, L. (2021). Burnout syndrome and association with work stress in nursing staff in public Hospital of the Northern Border of Mexico. Archives of Psychiatric Nursing.
(2) Ahmed, R.M., Abdelwahab E.A., and Elguindy, H. (2017). Staff nurses' intention to leave the nursing profession and their organizational commitment in selected hospitals at Beni-Sueif city. Egyptian Nursing Journal; 14 (1), 17- 24.

(3) Al Shaibani, W., Al-Qahtani, M., AlAmri, E., \& Khandekar, R. (2020). Magnitude and Determinants of Nurses' Perceived Stress and Burnout in a Tertiary Eye Hospital. Archives of Clinical and Medical Case Reports, 4(4), 724-732

(4) Ali, H. I. (2017). Societal factors that induce career change decision among nurses working at different Sohag city hospitals. Egyptian Nursing Journal, 14(2), 130.

(5) Andresen, I. H., Hansen, T., \& Grov, E. K. (2017). Norwegian nurses' quality of life, job satisfaction, as well as intention to change jobs. Nordic Journal of Nursing Research, 37(2), 90-99.

(6) Barthauer, L., Kaucher, P., Spurk, D., \& Kauffeld, S. (2020). Burnout and career (un) sustainability: Looking into the Blackbox of burnout triggered career turnover intentions. Journal of vocational behavior, 117, 103334.

(7) Blegen M.A, Good C.1,., and Johnson M. (1993). Preference for decision-making.Image $\mathrm{J}$ Nurs Sch; 25(4):339-44.

(8) Boughn, S. (2001). Why women and men choose nursing. Nursing Education Perspectives, 22(1), 14.

(9) Brzostek, T. (2020). Coaching in the professional and personal development of nurses. Pielegniarstwo XXI wieku/Nursing in the 21st Century, 19(1), 42-46.

(10) Chang, H. Y., Friesner, D., Chu, T. L., Huang, T. L., Liao, Y. N., \& Teng, C. I. (2018). The impact of Burnout on self $\square$ efficacy, outcome expectations, career interest, and nurse turnover. Journal of advanced nursing, 74(11), 25552565.

(11) Fooladi, M. M. (2003). Gendered nursing education and practice in Iran. Journal of Transcultural Nursing, 14(1), 32-38.

(12) Garcia, G. P. A., \& Marziale, M. H. P. (2021). Satisfaction, stress and burnout of nurse managers and care nurses in Primary Health Care. Revista da Escola de Enfermagem da USP, 55.

(13) Goodare, P. (2017). Literature review: Why do we continue to lose our nurses? Australian Journal of Advanced Nursing, The, 34(4), 50.

(14) Heinen, M. M., van Achterberg, T., Schwendimann, R., Zander, B., Mattews, A., Kózka, M., ... Schoonhoven, L. (2013). Nurses' intention to leave their profession: A crosssectional observational study in 10 European countries. International Journal of Nursing Studies, 50(2), 174-184

(15) Kaur, L., Kanika, K. A., \& KUMAR, A. (2016). Assess the attitude of nursing students towards the nursing profession. Int J Applied Res, 2(6), 738-741.

(16) Leone, C., Bruyneel, L., Anderson, J. E., Murrells, T., Dussault, G., de Jesus, É. H., ... \& Rafferty, A. M. (2015). Work environment issues and intention-to-leave in Portuguese nurses: A cross-sectional study. Health Policy, 119(12), 1584-1592.

(17) Lo, W. Y., Chien, L. Y., Hwang, F. M., Huang, N., \& Chiou, S. T. (2018). From job stress to intention to leave among hospital nurses: A structural equation modelling approach. Journal of advanced nursing, 74(3), 677-688.

(18) Maslach C, and Jackson SE, (2016). Maslach burnout inventory. https://www.mindgarden.com/117-maslachburnout-inventory-mbi

(19) Mohammed, R. R., Abdel Wahab, E. A., \& El-Sayed, R. I. (2020). Factors Influencing Career Development among Nursing Staff at Port-Said Governmental Hospitals. Port Said Scientific Journal of Nursing, 7(1), 191-211.

(20) Mueller C.W and McCloskey J.C. (1990). Job satisfaction: A proposed measure. Nursing Research; 39 (2):113-17. 
(21) Rosen, M. A., Dietz, A. S., Lee, N., Wang, I. J. Markowitz, J., Wyskiel, R. M., ... \& Pronovost, P. J. (2018). Sensor-based measurement of critical care nursing workload: Unobtrusive measures of nursing activity complement traditional task and patient-level indicators of workload to predict perceived exertion. PloS one, 13(10), e0204819.

(22) Occupational .(r.r.)Shafei, D. A. -R. M., \& El ‘Said stress, job satisfaction, and intent to leave: nurses working pandemic in Zagazig City, 19-on front lines during COVID - IEgypt. Environmental Science and Pollution Research, .11
(23) Habibzadeh, H., Alilu, L., ‘.Valizadeh, L., Zamanzadeh, V Experiences of Iranian . ( $(\cdot 17)$ Gillespie, M., \& Shakibi, A. nurses that intent to leave the clinical nursing: a content .179 ، $(r) \circ$ analysis. Journal of caring sciences,

(24) .( ( • I V)Woo, B. F. Y., Lee, J. X. Y., \& San Tam, W. W. he impact of the advanced practice nursing role on quality $T$ of care, clinical outcomes, patient satisfaction, and cost in the emergency and critical care settings: a systematic T 1 ( (1) 1 review. Human resources for health,

(25) d, D., \& McNeill, C. Yarbrough, S., Martin, P., Alfre Professional values, job satisfaction, career $(Y \cdot \mid V)$ ( (\urcorner$^{Y} Y$ development, and intent to stay. Nursing Ethics, .7NO-TVO 